\title{
HIGHLIGHTS OF RECENT
}

\section{IFPRI food policy research} for SWMTCERLAND

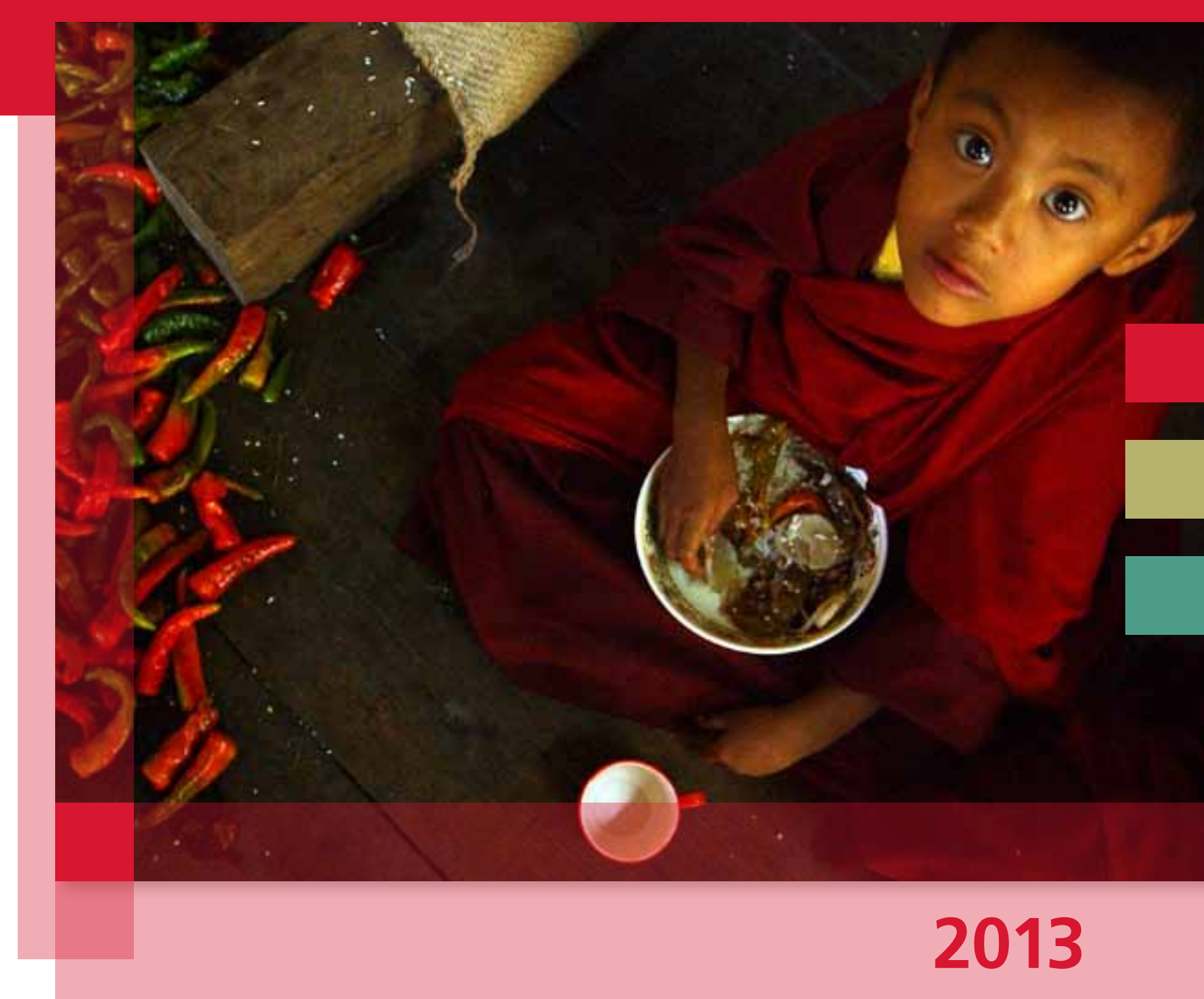

Reducing Poverty and Hunger through Food Policy Research 


\section{Foreword}

In the wake of the food crises of the early 1970s and the resulting World Food Conference of 1974, a group of innovators realized that food security depends not only on enhanced agricultural production, but also on the policies that affect food systems, from farm to table. In 1975, the International Food Policy Research Institute (IFPRI) was founded to provide solid research and evidence-based policy options to sustainably reduce poverty and end hunger and malnutrition.

Agriculture and rural development play a critical role in alleviating poverty and undernutrition. IFPRI's current research focuses on supporting sustainable agricultural growth, ramping up investment in agricultural research, providing safety nets to strengthen resilience, prioritizing nutrition interventions for women and children, ensuring property rights and appropriate management of natural resources, and building partnerships with stakeholders in global movements such as Scaling Up Nutrition (SUN).

Switzerland's 2012 budget moved the country closer to its 2015 goal of allocating 0.5 percent of its gross national income to foreign aid. A commitment of this magnitude is both essential to meeting the challenges we face as a global community and consistent with Switzerland's constitution, which pledges a commitment to "the relief of poverty and suffering in the world, respect for human rights and promotion of democracy, the peaceful co-existence between peoples, and the protection of the natural basis for life." Switzerland's dedication to investing in local, participatory programs as well as their grassroots approach to development provides a foundation for the necessary sustainable growth to effectively fight poverty.

Over several years, the unrestricted financial support from Switzerland has helped to ensure that IFPRI's research remains both responsive and innovative, tackling the obstacles that stand in the way of food security and poverty alleviation. With Switzerland's support, IFPRI is developing technological platforms such as the Food Security Portal, which provides up-to-date country-level information on food policy developments, as well as leading collective research efforts such as the CGIAR Research Program on Policies, Institutions and Markets (PIM).

Together with many longstanding partners, including Switzerland, IFPRI works to illuminate the pathway to improved food and nutrition security for the world's poor. Moreover, agricultural research is a good investment: every US\$1 invested in CGIAR research yields approximately $\$ 9$ worth of additional food in the developing world. This brochure highlights some of the key collaborations between IFPRI and Switzerland, often in partnership with other institutions. 


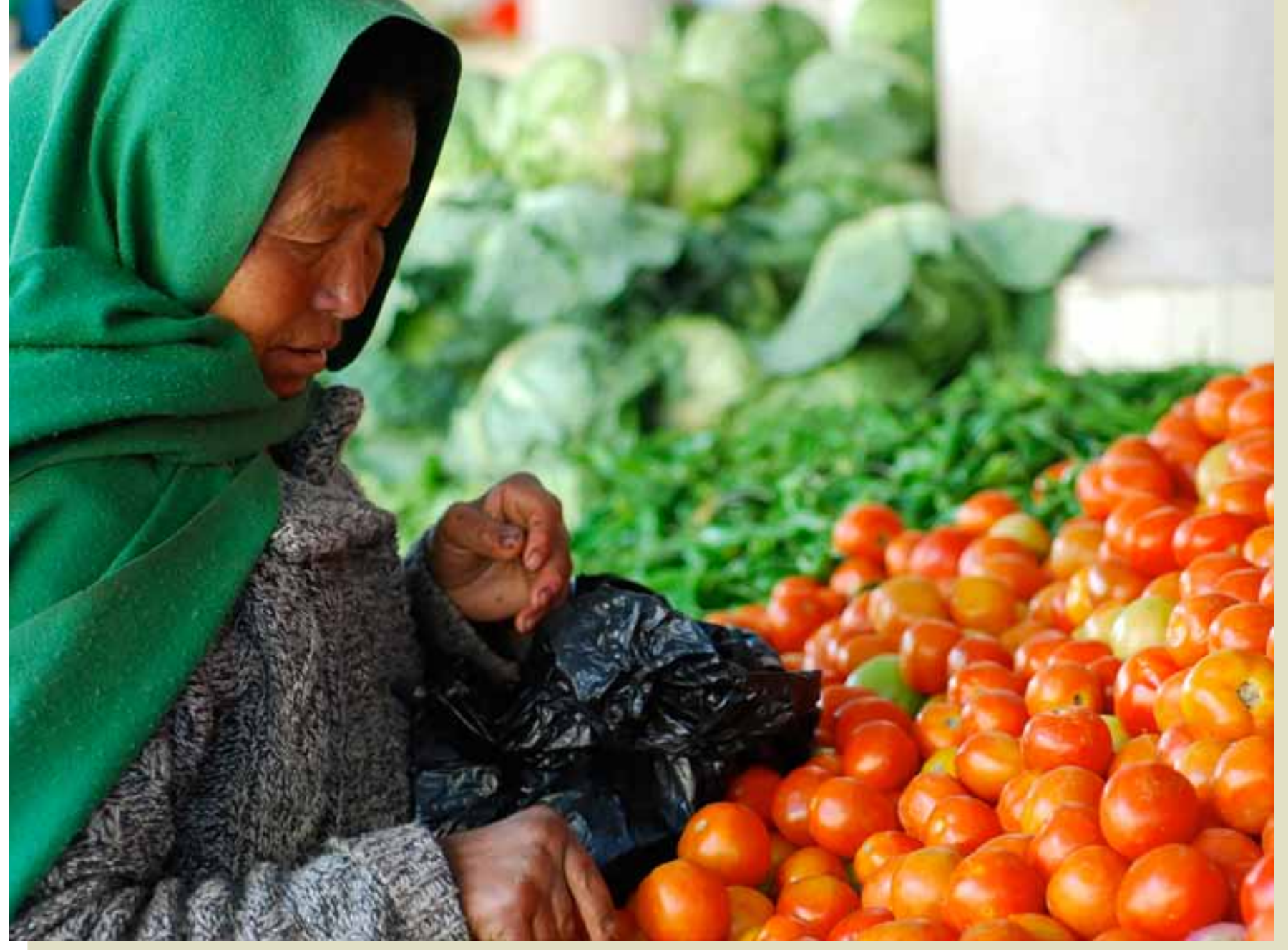

\section{Supporting Evidence-Based Agricultural Policy}

Agriculture, Food Policy Research, and Capacity

Strengthening in Bhutan

\section{MOTIVATION}

Over the past two decades, Bhutan has made great strides toward achieving food security. In 2010, IFPRI, in partnership with the Bhutanese Ministry of Agriculture and Forests and with support from the governments of Bhutan and Switzerland, developed a policy research and capacity-strengthening program in the country with two major objectives: (1) to design a comprehensive food policy strategy supported by sound empirical research and (2) to develop sustainable capacity for implementing future research on the emerging policy issues that affect the food, agriculture, and natural resource sectors in Bhutan.

IFPRI assisted in developing the Ministry of Agriculture's rice policy strategy. IFPRI also aided in expanding applied policy research, local capacity strengthening, promoting a scholar exchange program, and disseminating research findings. The program concluded with a workshop entitled Agricultural and Food Policy Research and Capacity Building.

\section{OUTCOMES}

- The data developed under this program was cited in the Government of Bhutan and the Food and Agriculture Organization of the United Nations' (FAO) 2013 Country Programming Framework for Bhutan.

- The 2012 FAO and World Bank report, Bhutan Agriculture Sector Review, cited the program data and stated, "More could be done to draw on the resources and expertise of the international research centres, following the example of the successful recent collaboration with IFPRI." 
- The 2008 G8 Summit report, Double Jeopardy: Responding to High Food and Fuel Prices, drew on IFPRI's research in its justification for the revision of biofuel policies.

- InfoResources, an SDC-funded Swiss network that produced and disseminated information on natural resources and international cooperation, cited IFPRI publications on the food price crisis in its 2009 report, When Food Markets Do Not Provide Enough Food: Lessons from the Recent Food Price Crisis.

\section{Ongoing Research}

The Food Security Portal

\section{MOTIVATION}

The Food Security Portal, supported by Switzerland, was established to provide relevant, up-to-date country-level information on food policy developments. The portal contains food security, food price, and demographic information on its 29 partner countriesmostly in Africa south of the Sahara, but also in Asia and Latin America and the Caribbean. The portal also

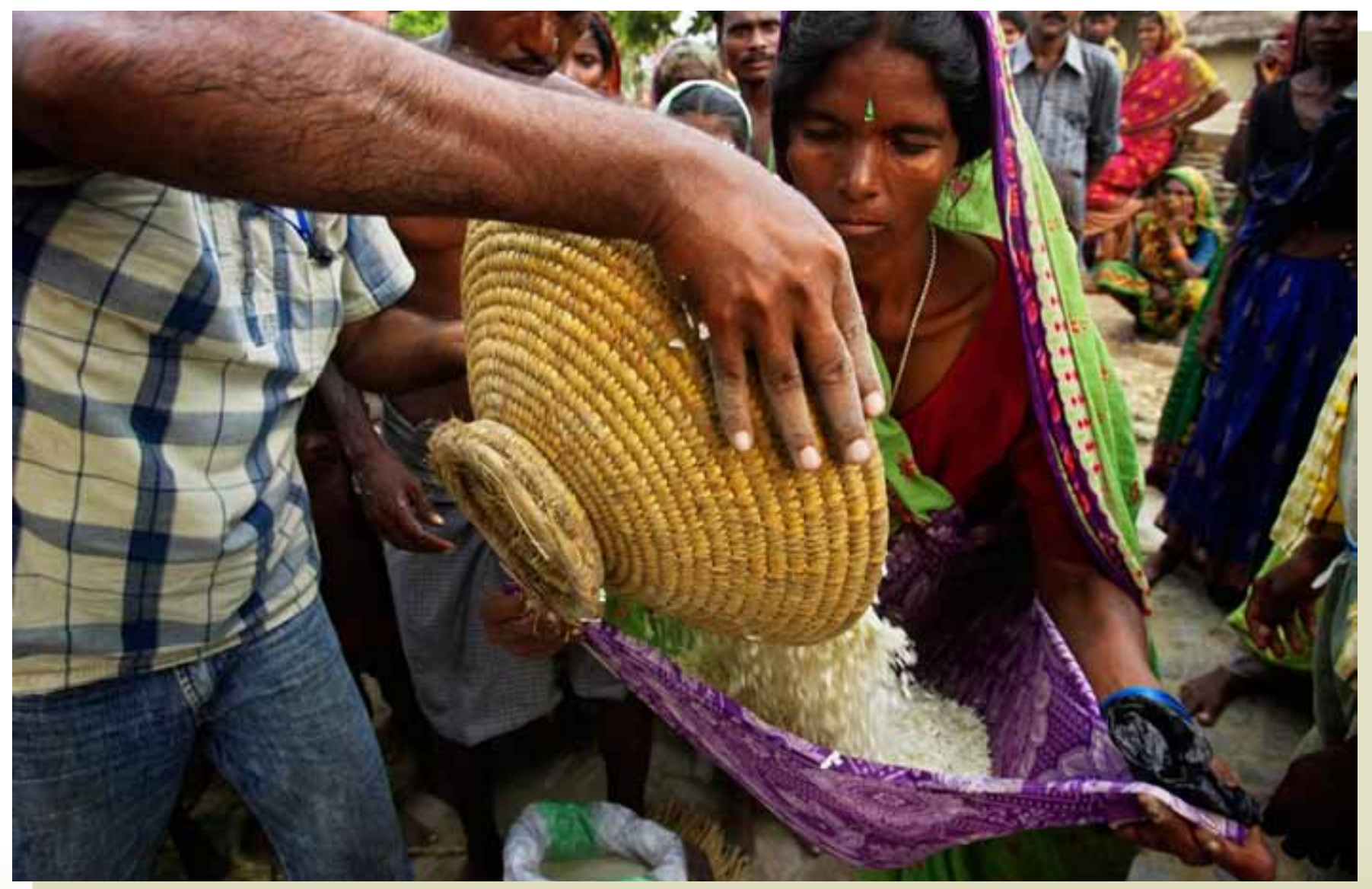


includes a research-based capacity-strengthening component, providing policy analysis tools to guide country-level responses and inform policymakers. One of the most important tools featured on the portal is the Excessive Food Price Variability Early Warning System, a dynamic alert system that tracks price volatility that dates back to 2000 and provides the daily price volatility status for five major agricultural commodities. The portal is featured on the UN Global Food Security website, and in the G20's Agricultural Markets Information System website. From October 2012 to October 2013, the portal has had nearly 78,000 unique visitors, with 58,000 of those coming from developing countries, particularly India and Kenya.

\section{Safety Net Transfer Modality Research Initiative} in Bangladesh

IFPRI and the UN World Food Programme (WFP) in Bangladesh, with support from Switzerland, jointly designed a pilot intervention to assess the impacts of various safety net transfer methods on behavior change: cash only, food only, and food and cash transfers in combination with nutrition education. The participants-4,000 ultra poor women and their 21,600 family members-have been receiving substantive benefits since May 2012. The pilot intervention aims to streamline Bangladesh's current social safety net system and to provide evidence to support the national social protection strategy.

Working with government agencies and development partners, the program targets poor and ultra poor social safety net beneficiaries in two regions with a particularly high incidence of food insecurity and nutrition deficiencies. WFP implements the pilot tests in the northwest and southwest of Bangladesh, and IFPRI assesses them using rigorous evaluation techniques. Primary findings include the following: (1) in the north, the country's poorest and most food insecure region, the interventions significantly increased participating households' food expenditures, calorie consumption, and income; and (2) in the south, a natural disaster prone region, the participating households tend to use the transfers for precautionary savings given the risk of future shocks, or to invest in assets. The research began in March 2012 and will conclude in January 2014.

\section{The CGIAR Research Program (CRP) on Policies,} Institutions and Markets (PIM)

CGIAR's research program on Policies, Institutions and Markets (PIM), led by IFPRI and launched in 2012, draws on the collective efforts of researchers from CGIAR centers to focus on areas critical to food security, poverty reduction, nutrition, and natural resource sustainability. With the generous support of partners such as Switzerland, PIM helps policymakers and others access timely research relevant to the decisions that affect our shared future food security.

PIM's research falls into seven flagship categories: Foresight Modeling, Science Policy and Incentives for Innovation, Adoption of Technology and Sustainable Intensification, Policy and Public Expenditure, Value Chains, Social Protection, and Natural Resource Property Regimes. PIM undertakes research directly relevant to policy choices currently under consideration and also develops tools and metrics to assess key trends in the global, national, and regional food systems. Research conducted under PIM is yielding the following results:

\section{- Foresight Modeling: Tested 20 promising} technologies to compare benefit streams. 
- Science Policy: The Program for Biosafety Systems is assisting seven countries with regulatory frameworks; the Agricultural Science and Technology Indicators initiative tracks spending on agricultural research.

- Sustainable Intensification: Innovations in agricultural extension were tested and adopted in East Africa.

- Policy and Public Spending: Updated methodology and data on agricultural public spending; developed Arab Spatial tools for policy analysis in the Middle East and North Africa; modeled biofuel policies.
- Value Chains: Tools and methods used by other CGIAR Research Programs; applications in Vietnam led to higher quality milk and better prices for smallholders.

- Social Protection: Research informs implementation of programs in several countries; for example, a review of Ethiopia's Productive Safety Nets Programme concluded that the program yielded benefits 29 times greater than the cost of research.

- Natural Resource Management: Strengthened strategy of commercialization for in situ conservation of biodiversity.

For more information, see http://www.pim.cgiar.org.

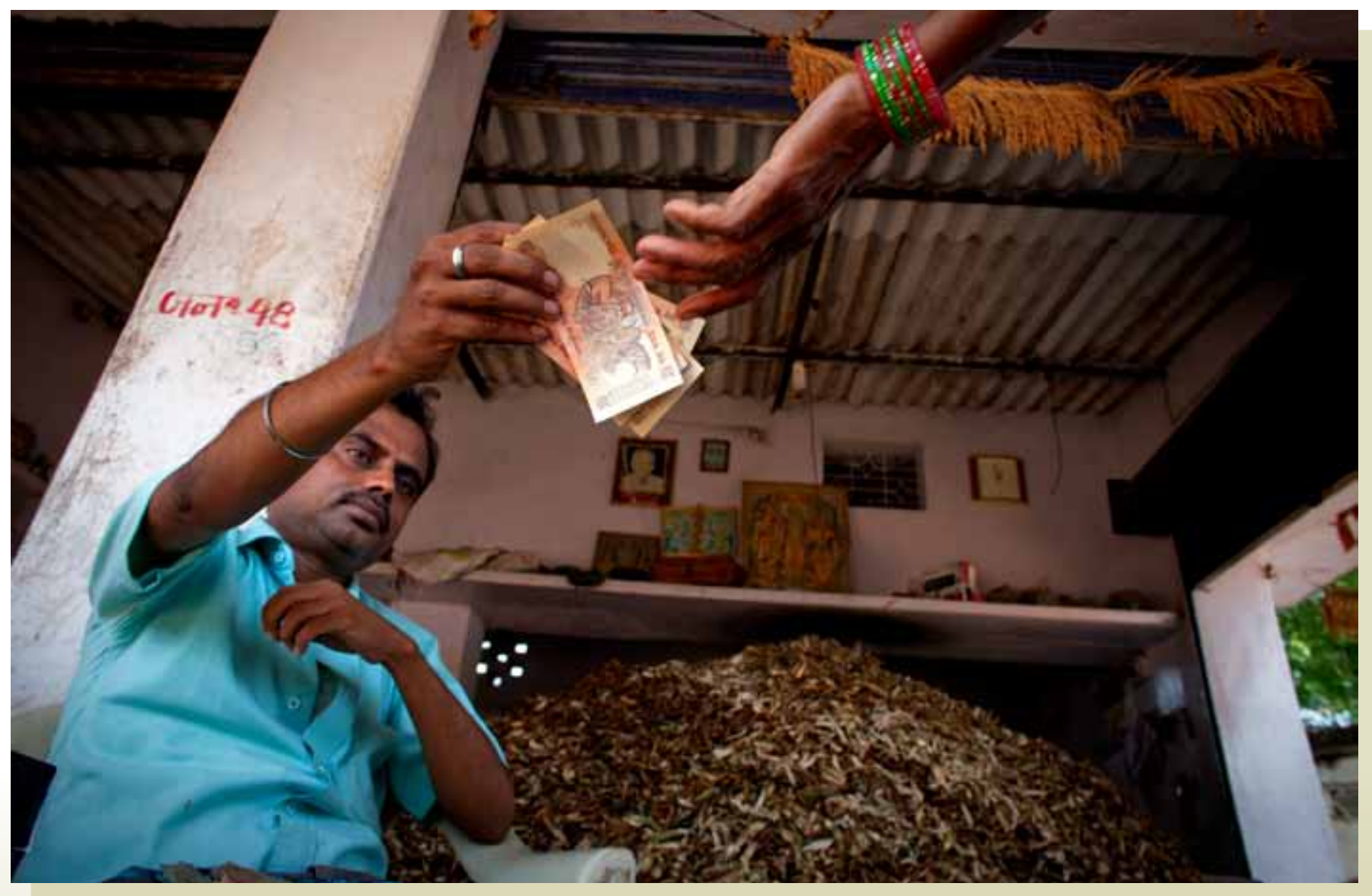




\section{IFPRI OFFICES AND COUNTRIES OF SIGNIFICANT RESEARCH}

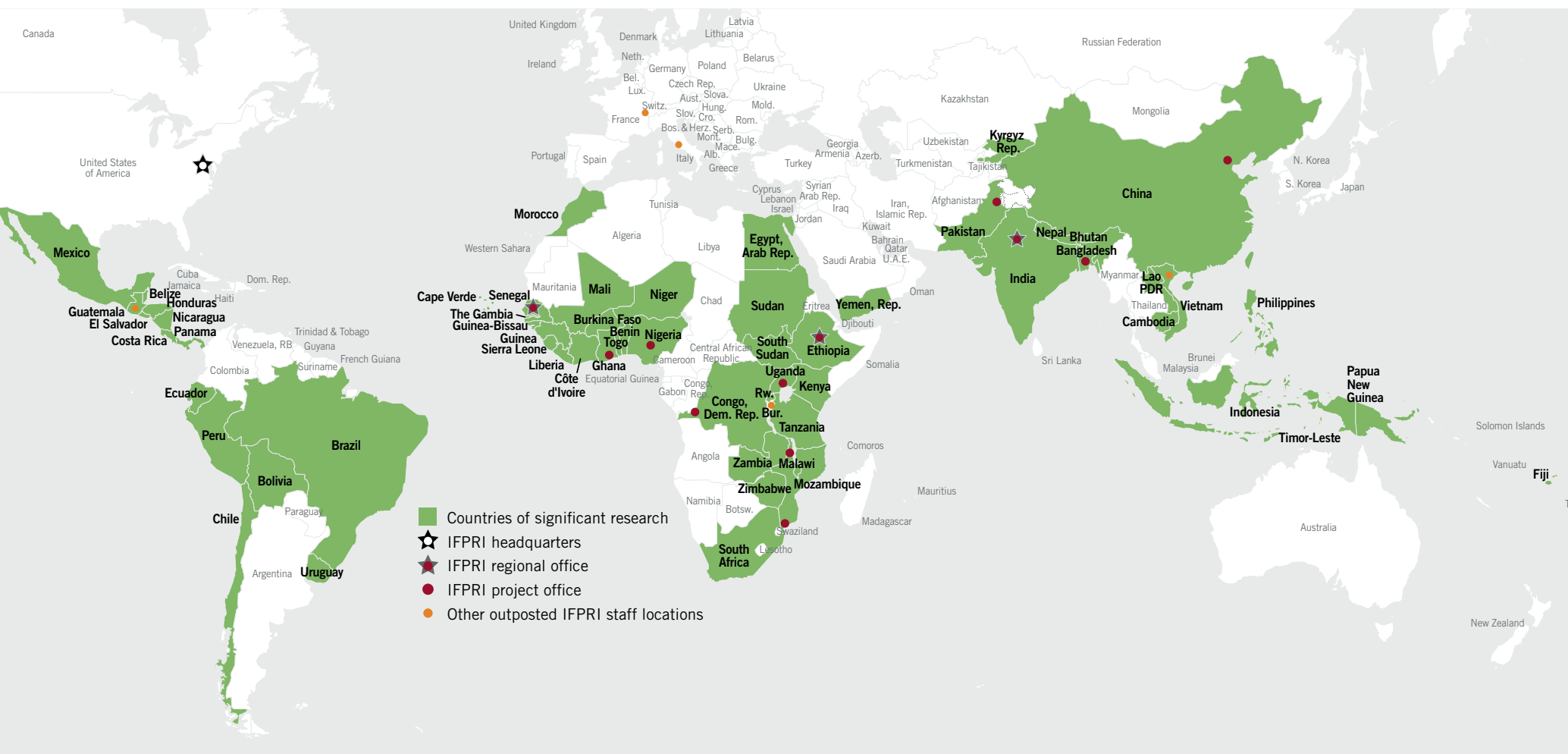

\section{Looking Forward}

The longstanding partnership between Switzerland and IFPRI has made great strides in improving food security, supporting economic transformation in developing countries, and reducing poverty and hunger around the world. As the world looks toward a post-2015 development agenda, the partnership between IFPRI and Switzerland will continue to support the cuttingedge research and development of measurable targets that increase agricultural productivity and tackle the root causes of hunger and poverty.

\section{INTERNATIONAL FOOD POLICY RESEARCH INSTITUTE}

A member of the CGIAR Consortium | A world free of hunger and malnutrition

$\begin{array}{llll}\text { IFPRI Headquarters } & \text { IFPRI Dakar } & \text { IFPRI Addis Ababa } & \text { IFPRI New Delhi } \\ 2033 \text { K Street, NW } & \text { Titre 3396, Lot \#2 } & \text { P.O. Box 5689 } & \text { NASC Complex, CG Block } \\ \text { Washington, DC 20006-1002 USA } & \text { BP 24063 } & \text { Addis Ababa, Ethiopia } & \text { Dev Prakash Shastri Road } \\ \text { Phone: +1-202-862-5600 } & \text { Dakar - Almadies, Senegal } & \text { Phone: +251-11-617-2500 } & \text { Pusa, New Delhi 110-012 India } \\ \text { Fax: +1-202-467-4439 } & \text { Phone: +221-33-869-9800 } & \text { Fax: +251-11-646-2927 } & \text { Phone: +91-11-2584-6565/66/67 } \\ \text { Email: ifpri@cgiar.org } & \text { Email: ifpri-dakar@cgiar.org } & \text { Email: ifpri-addisababa@cgiar.org } & \text { Fax: +91-11-2584-8008/2584-6572 } \\ \text { Web: www.ifpri.org } & & & \text { Email: ifpri-newdelhi@cgiar.org }\end{array}$

PHото CREDits: Cover-@ 2002 Ami Vitale/Panos. Page 3-@ 2012 Electraacity/Flickr. Page 4-@ 2007 G. M. B. Akash/Panos. Page 5-@ 2007 Jacob Silberberg/Panos. Page 7-@ 2010 Brian Sokol/Panos.

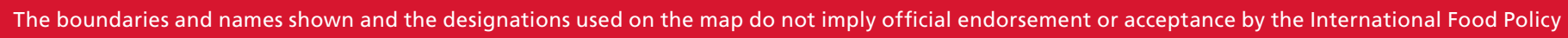
Research Institute (IFPRI). 